\title{
Genetic variation for tolerance to defoliation in Cirsium arvense (Californian thistle)
}

\author{
M.G Cripps ${ }^{1}$, C.A. Dowsett ${ }^{2}$, S.D. Jackman ${ }^{1}$, A.D.L. Noble ${ }^{1}$ and G.J. Houliston ${ }^{3}$ \\ ${ }^{1}$ AgResearch, Lincoln, Christchurch 8140, New Zealand \\ ${ }^{2}$ AgResearch, Ruakura Research Centre, Hamilton 3214, New Zealand \\ ${ }^{3}$ Landcare Research, Lincoln 7608, New Zealand \\ Corresponding author: mike.cripps@agresearch.co.nz
}

The pasture weed, Cirsium arvense (Californian thistle), is notorious for its ability to tolerate defoliation by herbivores, mowing, or herbicides, which is facilitated by the growth of adventitious shoots from its extensive clonal underground root system. In an outdoor potted-plant experiment, we examined the tolerance of 36 unique genotypes of $C$. arvense to defoliation by establishing pairs of clonal replicates that were assigned to a clipped, or unclipped treatment. Three clipping treatments were applied, and the final height, number of shoots, and biomass, were measured to compare the fitness between the clipped and unclipped clones. The majority of genotypes were negatively affected by clipping and showed a reduction in most final fitness measurements. However, some genotypes were equivalent or even greater than their unclipped counterparts indicating a large genetic range for tolerance to defoliation. The mean range in tolerance ratios (clipped/ unclipped) was 0.17 to 1.3 for shoot height, 0.26 to 1.2 for shoot density, and 0.6 to 1.2 for biomass (where a ratio of 1 indicates equivalence to the unclipped state). Since repeated defoliation is recommended for control of this weed, selection for more tolerant genotypes is possible, which may have management implications.

\section{Resistance of apple and pear rootstocks to Neonectria ditissima and their effect on scion susceptibility}

\author{
R.W.A. Scheper ${ }^{1}$, M. Walter ${ }^{2}$, B.M. Fisher ${ }^{1}$, S. Johnston ${ }^{1}$, T. Curnow ${ }^{2}$, N.T. Amponsah ${ }^{1}$, P. Alspach ${ }^{2}$ and \\ D.I. Hedderley ${ }^{3}$
}

${ }^{1}$ The New Zealand Institute for Plant \& Food Research Limited (PFR), Cnr Crosses and St George's Roads, Havelock North 4130, New Zealand

${ }^{2}$ PFR, Old Mill Road, Motueka, New Zealand

${ }^{3}$ PFR, Batchelar Road, Palmerston North 4474, New Zealand

Corresponding author: reiny.scheper@plantandfood.co.nz

The susceptibility of apple and pear rootstocks to European canker (Neonectria ditissima), and the effect of rootstocks on scion susceptibility are largely unknown. Bioassays were conducted to determine the susceptibility to European canker of selected apple and pear rootstocks, and 'Royal Gala' scions bench-grafted onto four apple rootstocks. Trials were conducted using potted trees in a glasshouse in Havelock North and field-planted trees in Motueka. Significant differences in susceptibility were observed among rootstocks, but the 'Royal Gala' scions were significantly more susceptible than the rootstocks. Accessions were exposed to a harsher test in the glasshouse, so fewer rootstocks were classified as "resistant". Nevertheless, rootstocks 'M116', 'MM106' and 'Quince C' showed high rates of resistance in both locations. Rootstock effects on the susceptibility of 'Royal Gala' were observed in the field but not in potted trees. In further testing using 'Royal Gala' and 'Golden Delicious' grafted onto four rootstocks, the the rootstock choice affected 'Royal Gala' susceptibility but not 'Golden Delicious'. 